\title{
CONDICIONAMENTO FISIOLÓGICO DE SEMENTES DE MILHETO ${ }^{1}$
}

\author{
FABRÍCIO BECKER PESKE ${ }^{2}$; ANA DIONISIA DA LUZ COELHO NOVEMBRE ${ }^{3}$
}

\begin{abstract}
RESUMO - A pesquisa foi realizada com o objetivo de avaliar o condicionamento fisiológico de sementes de três lotes de milheto do cultivar BRS 1501. Os tratamentos consistiram da testemunha, sementes hidratadas em água pura (potencial zero) e em oito potenciais de solução aquosa de PEG $6000(-0,1 ;-0,2 ;-0,4 ;-0,6 ;-0,8 ;-1,0 ;-1,2$ e -1,4 MPa). As sementes foram avaliadas quanto ao teor de água, germinação (total e primeira contagem de germinação), emergência da plântula (total e índice de velocidade de emergência da plântula), testes de envelhecimento acelerado e de condutividade elétrica. Os resultados indicaram que as sementes de milheto emitem a raiz primária ao atingirem 33\% de água, porém, como esperado, na medida em que aumentou a concentração de PEG, maior foi o período necessário para absorção de água, sendo que para os potenciais de $-1,2$ e -1,4 MPa as sementes não absorveram mais do que $28 \%$ de água e, assim, não emitiram a raiz primária. As sementes de milheto do cultivar BRS 1501 emitem a raiz primária com 33\% de água, em potencial hídrico de zero $\mathrm{MPa}$. O condicionamento fisiológico das sementes de milheto, utilizando água ou PEG 6000, não interfere no desenvolvimento inicial das plântulas.
\end{abstract}

Termos para indexação: Pennisetum glaucum, teor de água, osmocondicionamento.

\section{PHYSIOLOGICAL CONDITIONING OF PEARL MILLET SEEDS}

\begin{abstract}
The objective of this study was to evaluate the physiological conditioning of three pearl millet seed lots of the BRS1501 commercial cultivar. The treatments consisted of untreated seeds, seeds hydrated with pure water and seeds hydrated with water of eight different potentials provided by PEG $6000(-0.1 ;-0.2 ;-0.4 ;-0.6 ;-0.8 ;-1.0 ;-1.2$ and $-1.4 \mathrm{MPa})$. The seeds were evaluated for water content, germination (first count of germination and final percentage), seedling emergence (final percentage and seedling emergence speed), accelerated ageing and electrical conductivity. The results showed that pearl millet seeds emit primary roots at 33\% water content, but as expected, the higher the PEG 6000 concentration, the longer the imbibition period necessary. For the potentials of -1.2 and $-1.4 \mathrm{MPa}$, the seeds did not absorb more than $28 \%$ of water, and thus, did not emit primary roots. The pearl millet seeds, cultivar BRS 1501 , emit the primary root at $33 \%$ water content, at a potential of zero MPa. It can be concluded that the physiological conditioning of pearl millet seeds by using pure water or PEG 6000, does not interfere in the initial seedling development.
\end{abstract}

Index terms: Pennisetum glaucum, seed water content, osmoconditioning.

${ }^{1}$ Submetido em 01/11/2009. Aceito para publicação em 01/06/2010.

${ }^{2} \mathrm{MSc}$ Eng. Agr., pós graduando do Departamento de Produção Vegetal, USP/ESALQ, fpeske@yahoo.com.br.
${ }^{3}$ Eng. Agr., Dr., Professor Doutor, Departamento de Produção Vegetal, USP/ESALQ, Caixa Postal 9, 13418 -900.Piracicaba, e-mail: adlcnove@ esalq.usp.br. 


\section{INTRODUÇÃO}

A planta do milheto é utilizada para alimentação de bovinos como forrageira anual, de verão e de inverno, por pastoreio direto ou como forragem pelo corte das plantas, como feno e como silagem, para a produção de grãos para consumo humano e para ser cultivada para a produção de palha em sistema de cultivo por plantio direto (Salton e Kichel, 1997).

Apesar de suas diversas aptidões de uso, alguns fatores são limitantes para a expansão do cultivo de milheto no Brasil, sendo, geralmente, a baixa qualidade física e fisiológica das sementes comercializadas, um dos principais agravantes.

O condicionamento fisiológico de sementes têm sido estudado e utilizado ao longo dos anos (Heydecker e Coolbear, 1977), especialmente para sementes pequenas e de alto valor agregado, como algumas espécies de hortaliças e de gramíneas que também têm sementes pequenas (Jett et al, 1996; Tallowin et al., 1994).

Para o condicionamento fisiológico, deve haver o controle da quantidade de água absorvida pela semente, com o desenvolvimento das fases iniciais da germinação (fases I e II), mas sem atingir o estádio de emergência da raiz primária (fase III), segundo o padrão trifásico proposto por Bewley e Black (1994).

O condicionamento osmótico ou "priming"é uma técnica que consiste no contato das sementes com solução osmótica, em tempo e temperatura previamente determinados (Anwar et al., 1978). As soluções osmóticas mais conhecidas são o polietileno glicol (PEG), o manitol e os sais inorgânicos ( $\mathrm{NaCl}, \mathrm{MgSO}_{4}$ e $\mathrm{KNO}_{3}$ ).

Ao trabalharem com diferentes genótipos de sementes de girassol, Mwale et al. (2003) afirmaram que o condicionamento osmótico das sementes com PEG 8000 em potencial de -0,6 MPa causou efeitos positivos em diferentes aspectos da germinação da semente e emergência da plântula, porém não influenciou os resultados referentes à formação de matéria seca e produtividade das plantas subseqüentes. No entanto, salientaram que, embora os efeitos tenham sido observados apenas na fase inicial de desenvolvimento da cultura, tais ganhos foram positivos e essenciais para o estabelecimento das plantas em campo, sendo uma alternativa para sincronizar o desenvolvimento de genótipos diferentes para a produção de sementes híbridas como, por exemplo, as linhagens "macho" ou "fêmea".

Embora o polietileno glicol seja o material mais utilizado dentre os sais para alterar o potencial osmótico da solução, por ser quimicamente inerte, não atravessar o sistema de membranas e não causar efeitos adversos ao embrião (Parera e Cantliffe, 1994), os resultados gerados têm variado quanto ao desempenho das sementes após o condicionamento. Enquanto alguns pesquisadores obtiveram respostas positivas (Chojnowski et al., 1997), outros observaram que o condicionamento com água pura ou "hidropriming" é suficiente para respostas efetivas (Fanan e Novembre, 2007; Prisco et al., 1992; Capron et al., 2000; Sivritepe e Eris, 2000).

Pesquisando diferentes tipos de condicionamento, Venkatasubramanian e Umarani (2007) demonstraram que o condicionamento fisiológico ideal varia de espécie para espécie, ao determinarem para as sementes de tomate que o condicionamento com resultados mais adequados foi o "hidropriming" por $48 \mathrm{~h}$, enquanto que para as sementes de berinjela e de pimentas o condicionamento ideal foi o mátrico utilizando areia com $80 \%$ de retenção de água.

No entanto Smith e Cobb (1991) ao trabalharem com sementes de pimenta, concluíram que a resposta ao condicionamento osmótico é dependente da duração do tratamento e do potencial osmótico e independente do tipo de sal utilizado.

No caso de sementes de gramíneas forrageiras há quantidade limitada de estudos e informações a respeito do condicionamento fisiológico, sendo os mais comuns para as de brachiárias (Bonome et al., 2006) e as de sorgo (Carvalho, 2000). Porém estudos realizados com outras espécies de gramíneas também têm sido promissores, como é o caso das sementes de cevada, para as quais segundo Abdulrahmani et al. (2007), houve eficiência dos condicionamentos com água pura, com PEG e $\mathrm{CaCl}_{2}$ e, até mesmo, com soluções nutritivas de fósforo.

Para as sementes de milheto Gaspar e Nakagawa (2002) avaliaram a absorção de água pelas sementes de três lotes do cv. Comum, demonstrando que a embebição, fase I do padrão trifásico de absorção de água encerrou-se em torno de 12 horas, a $25{ }^{\circ} \mathrm{C}$, quando as sementes tinham mais de $35 \%$ de água e após 20 horas de hidratação, mais de $80 \%$ das sementes apresentaram emissão de raiz primária.

Logo, o objetivo desta pesquisa foi avaliar o condicionamento fisiológico de sementes de milheto através do condicionamento osmótico com PEG 6000 e com água pura.

\section{MATERIAL E MÉTODOS}

O estudo foi realizado no laboratório de sementes do Departamento de Produção Vegetal da Escola 
Superior de Agricultura "Luiz de Queiroz" (ESALQ), da Universidade de São Paulo (USP).

As sementes de milheto foram representadas por três lotes do cultivar BRS 1501, as quais foram submetidas à hidratação em água pura (zero $\mathrm{MPa}$ ) e em oito concentrações de polietilenoglicol (PEG 6000), que proporcionaram os seguintes potenciais a $25{ }^{\circ} \mathrm{C}$ : 0,0 ; $-0,1 ;-0,2 ;-0,4 ;-0,6 ;-0,8 ;-1,0 ;-1,2$ e -1,4 MPa.

Para que fosse determinado o período de hidratação mais adequado para cada tratamento, foram realizadas avaliações para determinar a absorção de água pelas sementes de milheto utilizando a água pura e as concentrações de PEG previamente indicadas. Para tal, quatro repetições de cinco gramas de sementes, com teor de água inicial previamente determinado, pelo método da estufa a $105 \pm 3{ }^{\circ} \mathrm{C}$ por $24 \mathrm{~h}$ (Brasil, 1992), foram submetidas à hidratação em rolos de papel a $25^{\circ} \mathrm{C}$. O teor de água das sementes foi avaliado em intervalos de uma hora até o momento da emissão da raiz primária. O ganho de água em porcentagem foi calculado pela fórmula: peso inicial $\mathrm{x}(100-$ umidade inicial $)=$ peso final x (100 - umidade final).

O período de hidratação escolhido para cada tratamento foi relativo ao tempo necessário para que a média de teor de água das sementes fosse suficiente para que não houvesse emissão da raiz primária de nenhuma semente em condicionamento. Logo, cada tratamento exigiu um período de hidratação específico, em função das diferenças de potencial osmótico das soluções. Sendo assim, os períodos de hidratação dos potencias de 0,$0 ;-0,1 ;-0,2 ;-0,4 ;-0,6 ;-0,8 ;-1,0$ MPa para o condicionamento fisiológico das sementes, foram de 6 , $8,8,8,10,12$ e 12 horas, respectivamente. Totalizando assim, para cada lote de sementes, sete tratamentos de condicionamento fisiológico e a testemunha.

O condicionamento fisiológico consistiu em colocar cinco repetições de três gramas de sementes de cada lote entre camadas de folhas de papel toalha umedecidas com água ou com as soluções de PEG 6000, envolvidas em sacos plásticos e mantidas na posição vertical em um germinador a $25{ }^{\circ} \mathrm{C}$, até que as sementes atingissem os teores de água estabelecidos para cada período de hidratação; em seguida as sementes foram lavadas em água corrente para retirar o excesso de solução de PEG 6000 .

Finalmente, as sementes foram secas a $30{ }^{\circ} \mathrm{C}$, em estufa com circulação de ar, até atingirem teores de água similares aos iniciais. As sementes foram acondicionadas em sacos de papel e armazenadas a $20{ }^{\circ} \mathrm{C}$ para as avaliações posteriores.

As soluções de polietileno glicol empregadas, para obter os potenciais hídricos respectivos, foram preparadas de acordo com a tabela de concentração de polietileno glicol, em função da temperatura e potencial osmótico, indicada por Villela et al. (1991).

As sementes foram avaliadas quanto ao teor de água, germinação (primeira contagem e germinação total) e quanto ao vigor pela emergência da plântula (porcentagem e índice de velocidade de emergência da plântula) e pelos testes de envelhecimento acelerado e de condutividade elétrica.

Teor de água (TA): determinado pelo método da estufa, conforme as Regras para Análise de Sementes - RAS (Brasil, 1992), com os resultados expressos em porcentagem de água (bu).

Primeira contagem de germinação (PC): foi determinada pela porcentagem de plântulas normais germinadas no quarto dia após a instalação do teste de germinação (Brasil, 1992).

Germinação (G): quatro repetições de 50 sementes para cada lote foram colocadas para germinar sobre folhas de papel toalha, umedecidas com quantidade de água equivalente a 2,5 vezes a massa do papel seco, a $25{ }^{\circ} \mathrm{C}$. Os resultados foram expressos em porcentagem de plântulas normais, determinada no sétimo dia após a instalação do teste de germinação (Brasil, 1992).

Emergência da plântula (EP): foi realizada com 400 sementes por lote, sendo cada repetição de 100 sementes distribuídas em sulcos de $4 \mathrm{~m}$ de comprimento, com 5 $\mathrm{cm}$ de profundidade (Nakagawa, 1999). A avaliação das plântulas emergidas foi realizada no sétimo dia após semeadura. $\mathrm{O}$ resultado final obtido e, a média das repetições expressa em porcentagem.

Índice de velocidade de emergência de plântulas (IVE): as avaliações foram realizadas diariamente, utilizando a metodologia descrita por Nakagawa, (1999). O número de plântulas emergidas diariamente foi dividido pelo número de dias decorridos entre a semeadura e a emergência. O resultado foi expresso em número médio de plântulas emergidas por dia.

Envelhecimento acelerado (EA): as amostras das sementes de cada lote foram distribuídas sobre uma tela suspensa no interior de caixas plásticas contendo $40 \mathrm{~mL}$ de água destilada. As caixas foram mantidas em incubadora do tipo BOD, regulada a $41{ }^{\circ} \mathrm{C}$, durante 48 horas (Garcia e Menezes, 1999). Após este período de 
exposição, as sementes foram colocadas para germinar conforme descrição anterior e com avaliação aos quatro dias. Os resultados foram expressos em porcentagem de plântulas normais.

Condutividade elétrica (CE): realizado seguindo as recomendações descritas por Vieira e Carvalho (1994), com quatro repetições de 50 sementes por lote. As sementes foram pesadas previamente e colocadas em copos plásticos, contendo $100 \mathrm{~mL}$ de água destilada e, a seguir, mantidas a $25^{\circ} \mathrm{C}$; após 24 horas de hidratação foi determinada a condutividade elétrica da solução de hidratação das sementes e o resultado foi expresso em $\mu$ S.cm. ${ }^{-1} \mathrm{~g}^{-1}$ de semente.

Para realização da análise estatística foi utilizado o delineamento experimental inteiramente casualizado, em quatro repetições e oito tratamentos (água pura, seis concentrações de PEG 6000 e a testemunha) para os três lotes de sementes. Os dados referentes às avaliações fisiológicas foram submetidos à análise de variância através do teste de $\mathrm{F}$ a $5 \%$ de probabilidade, e estudo de regressão polimonial.

\section{RESULTADOS E DISCUSSÃO}

A evolução da absorção de água pelas sementes de milheto, dos três lotes do cultivar BRS1501, em diferentes potenciais hídricos providos a partir de diferentes concentrações de PEG 6000 e água pura (potencial zero $\mathrm{MPa}$ ), indicou que para o potencial zero há o início da protrusão da raiz primária quando o teor de água das sementes é superior a $33 \%$, cujo período mínimo de hidratação foi de 10 horas para as sementes de todos os lotes avaliados (Tabelas, 1, 2 e 3 ).

Para os potenciais de $-0,1 ;-0,2$ e $-0,4 \mathrm{MPa}$, o período de hidratação necessário para protrusão da raiz primária foi, em média, de 12 horas. Sendo que, para as sementes do lote 1 , o teor de água foi, em média, $3 \%$ menor do que ao das sementes submetidas à embebição sob potencial zero e, para os lotes 2 e 3 , o teor de água foi $4 \%$ e $1 \%$ menor, respectivamente.

TABELA 1. Teor de água (\%) de sementes de milheto do lote 1 , cultivar BRS 1501 durante a hidratação, a $25^{\circ} \mathrm{C}$.

\begin{tabular}{cccccccccc}
\hline \multirow{2}{*}{ Hidratação (h) } & \multicolumn{7}{c}{ Potenciais osmóticos (MPa) } \\
\cline { 2 - 10 } & Zero & $-0,1$ & $-0,2$ & $-0,4$ & $-0,6$ & $-0,8$ & $-1,0$ & $-1,2$ & $-1,4$ \\
\hline 0 & 10,9 & 10,9 & 10,9 & 10,9 & 10,9 & 10,9 & 10,9 & 10,9 & 10,9 \\
2 & 24,6 & 21,0 & 23,2 & 16,8 & 18,6 & 16,9 & 18,0 & 15,1 & 14,7 \\
4 & 27,5 & 25,2 & 23,8 & 19,8 & 23,4 & 20,2 & 22,5 & 18,6 & 20,9 \\
6 & 30,4 & 26,5 & 26,2 & 23,0 & 25,2 & 21,5 & 23,9 & 20,0 & 24 \\
8 & 31,6 & 28,6 & 28,9 & 24,9 & 27,6 & 23,5 & 25,6 & 22,9 & 25,3 \\
10 & $33,2^{*}$ & 29,3 & 29,6 & 27,9 & 29,3 & 25,9 & 27,5 & 23,8 & 26 \\
12 & --- & $30,4^{*}$ & $30,1^{*}$ & $30,8^{*}$ & 29,9 & 28,7 & 29,3 & 27,2 & 26,6 \\
14 & --- & --- & --- & --- & $30,4 *$ & $30,9 *$ & $30,1 *$ & 27,9 & 27 \\
16 & --- & --- & --- & --- & --- & --- & --- & 28,7 & 28,1 \\
18 & --- & --- & --- & --- & --- & --- & --- & 29,4 & 28,2 \\
20 & --- & --- & --- & --- & --- & --- & --- & 29,4 & 28,2 \\
\hline
\end{tabular}

*Emissão da raiz primária. 
TABELA 2. Teor de água (\%) de sementes de milheto do lote 2 , cultivar BRS 1501, durante a hidratação, a $25^{\circ} \mathrm{C}$.

\begin{tabular}{clllllllll}
\hline \multirow{2}{*}{ Hidratação (h) } & \multicolumn{7}{c}{ Potenciais osmóticos (MPa) } \\
\cline { 2 - 10 } & Zero & $-0,1$ & $-0,2$ & $-0,4$ & $-0,6$ & $-0,8$ & $-1,0$ & $-1,2$ & $-1,4$ \\
\hline 0 & 10,1 & 10,1 & 10,1 & 10,1 & 10,1 & 10,1 & 10,1 & 10,1 & 10,1 \\
2 & 23,2 & 22,2 & 21,7 & 21,1 & 17,9 & 17,4 & 17,5 & 17,3 & 15,1 \\
4 & 29,7 & 25,8 & 25,2 & 25,0 & 22,6 & 22,5 & 21,6 & 19,4 & 17,6 \\
6 & 33,1 & 26,5 & 27,2 & 27,9 & 24,4 & 24,7 & 24,4 & 24,6 & 20,0 \\
8 & 34,0 & 29,3 & 31,0 & 29,5 & 27,0 & 25,6 & 25,7 & 25,9 & 23,8 \\
10 & $35,4^{*}$ & $31,0^{*}$ & 31,5 & 30,0 & 29,1 & 27,5 & 26,9 & 27,0 & 26,0 \\
12 & --- & --- & $31,7^{*}$ & $30,9^{*}$ & $30,5^{*}$ & $30,6^{*}$ & 28,4 & 27,8 & 27,1 \\
14 & --- & --- & --- & --- & --- & --- & $31,0^{*}$ & 29,2 & 28,2 \\
16 & --- & --- & --- & --- & --- & --- & --- & 29,2 & 28,5 \\
18 & --- & --- & --- & --- & --- & --- & --- & 29,2 & 28,5 \\
\hline
\end{tabular}

*Emissão da raiz primária.

TABELA 3. Teor de água (\%) de sementes de milheto do lote 3 , cultivar BRS 1501, durante a hidratação, a $25^{\circ} \mathrm{C}$.

\begin{tabular}{cccccccccc}
\hline \multirow{2}{*}{ Hidratação $(\mathrm{h})$} & \multicolumn{7}{c}{ Potenciais omóticos (MPa) } \\
\cline { 2 - 10 } & Zero & $-0,1$ & $-0,2$ & $-0,4$ & $-0,6$ & $-0,8$ & $-1,0$ & $-1,2$ & $-1,4$ \\
\hline 0 & 10,4 & 10,4 & 10,4 & 10,4 & 10,4 & 10,4 & 10,4 & 10,4 & 10,4 \\
2 & 23,2 & 21,6 & 20,3 & 16,4 & 17,8 & 17,7 & 17,4 & 16,8 & 15,6 \\
4 & 29,2 & 24,8 & 23,6 & 19,3 & 22,9 & 22,1 & 22,5 & 21,8 & 18,9 \\
6 & 32,4 & 24,6 & 26,1 & 22,6 & 25,4 & 24,0 & 25,3 & 23,7 & 21,5 \\
8 & 33,9 & 30,2 & 27,6 & 24,5 & 26,9 & 26,5 & 26,4 & 24,7 & 25,0 \\
10 & $34,0^{*}$ & 31,8 & $31,7 *$ & 28,8 & 28,3 & 28,9 & 27,5 & 25,4 & 26,0 \\
12 & --- & $32,8 *$ & --- & $32,8^{*}$ & 29,9 & 30,7 & 28,5 & 26,3 & 27,2 \\
14 & --- & --- & --- & --- & $31,4 *$ & $31,7 *$ & $30,3 *$ & 26,9 & 27,9 \\
16 & --- & --- & --- & --- & --- & --- & --- & 28,0 & 28,4 \\
18 & --- & --- & --- & --- & --- & --- & --- & 28,5 & 28,5 \\
20 & --- & --- & --- & --- & --- & --- & --- & 28,9 & 28,9 \\
22 & --- & --- & --- & --- & --- & --- & --- & 29,7 & 28,9 \\
24 & --- & --- & --- & --- & --- & --- & --- & 29,7 & 28,9 \\
\hline
\end{tabular}

*emissão da raiz primária.

Para os potenciais de $-0,6 ;-0,8$ e -1,0 MPa, o período de hidratação foi, em média, de 14 horas, com exceção dos potenciais - 0,6 e $-0,8 \mathrm{MPa}$ do lote 2, para os quais foram necessárias 12 horas para o início da protrusão da raiz primária. Assim, ao serem comparados com o tratamento em potencial zero é possível observar que, ao haver o inicio da protrusão da raiz primária, o teor médio de água das sementes dos três lotes foi menor para todos os tratamentos com potenciais negativos das soluções aquosas de PEG 6000 .

O período mais significativo de absorção de água pelas sementes foram as duas horas iniciais de hidratação, cuja amplitude atingiu, no mínimo, $100 \%$ de incremento de água para os tratamentos com potencial zero, para todos os três lotes. Enquanto que para o potencial de -1,4 MPa de PEG 6000 , o incremento no teor de água nas duas horas iniciais 
foi, em média, de apenas 50\%. Evidenciando assim, a amplitude do efeito do potencial negativo do meio aquoso nos primeiros momentos de embebição das sementes.

Resultados similares foram obtidos por Gaspar e Nakagawa (2002), os quais verificaram que a maior absorção de água pelas sementes de milheto ocorreu nas duas horas iniciais, acompanhando o modelo trifásico de absorção de água durante o processo de germinação. Sendo que, a partir do período de 20 horas de hidratação, para as sementes dos lotes 1 e 2, e a partir de 22 horas, para as do lote 3 , mais de $80 \%$ haviam emitido a raiz primária e em relação ao teor de água, as sementes dos três lotes tinham, no mínimo, $37 \%$ de água.

Para os potenciais de $-1,2$ e $-1,4 \mathrm{MPa}$, as sementes não atingiram $32 \%$ de água e, assim, não emitiram raiz primária, cessando a hidratação com $28 \%$ de água para todos os lotes, com 16 h de hidratação. Por essa razão, os tratamentos envolvendo o condicionamento das sementes com esses potenciais não foram avaliados nessa pesquisa.

De acordo com estes resultados, é possivel considerar que potenciais negativos, iguais ou inferiores a -1,2 e -1,4 $\mathrm{MPa}$, interferem siginificativamente na absorção de água pelas sementes de milheto, comprometendo a germinação e a emergência da plântula em campo.

Como observado na Tabela 4, o condicionamento fisiológico, tanto com água como com PEG 6000, não apresentou efeitos significativos para as avaliações de germinação, índice de velocidade de emergência e emergência das plântulas e teor de água das sementes. Porém, o condicionamento fisiológico apresentou efeitos significativos para as variáveis tratamentos, lote e interação entre lotes e tratamentos, para as avaliações de envelhecimento acelerado e de primeira contagem de germinação, além de efeitos significativos para lote e tratamento no teste de condutividade elétrica.

TABELA 4. Resultado da análise de variância para os testes de germinação (G), primeira contagem da germinação (PC), índice de velocidade de emergência da plântula (IVE) e total de emergência da plântula (EP), envelhecimento acelerado (EA) e condutividade elétrica (CE) e teor de água (TA) de sementes de milheto do cultivar BRS 1501, em função dos tratamentos.

\begin{tabular}{lccccccc}
\hline & PC & G & EA & CE & IVE & EP & TA \\
\hline Tratamentos (T) & $*$ & $\mathrm{~ns}$ & $* *$ & $*$ & $\mathrm{~ns}$ & $\mathrm{~ns}$ & $\mathrm{~ns}$ \\
Lotes (L) & $* * *$ & $\mathrm{~ns}$ & $*$ & $*$ & $\mathrm{~ns}$ & $\mathrm{~ns}$ & $\mathrm{~ns}$ \\
$\mathrm{~T} \mathrm{x} \mathrm{L}$ & $* * *$ & $\mathrm{~ns}$ & $* *$ & $\mathrm{~ns}$ & $\mathrm{~ns}$ & $\mathrm{~ns}$ & $\mathrm{~ns}$ \\
\hline $\mathrm{CV}(\%)$ & 7,28 & 7,15 & 10,32 & 8,22 & 9,45 & 8,92 & 17,91 \\
\hline
\end{tabular}

* Significativos: $\mathrm{P}<0,05^{*} ; \mathrm{P}<0,01 * * ; \mathrm{P}<0,001 * * * ; n s=$ não-significativo $(\mathrm{P}>0,05)$

A avaliação de primeira contagem, como observado na Figura 1, demonstrou haver um ajuste cúbico para o efeito de condicionamento fisiológico sob diferentes potenciais osmóticos para a porcentagem de plântulas normais observada, cujo coeficiente de determinação de 0,95 explica a variação para o lote de menor qualidade fisiológica inicial (lote 1).

As sementes do lote 1 apresentaram resultados com variação de até 14 pontos percentuais entre as sementes não condicionadas e as condicionadas sob o potencial osmótico de -0,8 MPa, enquanto, para as sementes do lote 3 , apenas os tratamentos com potencial abaixo de $-0,1$ $\mathrm{MPa}$ foram inferiores às sementes não condicionadas, o que é explicado pelo coeficiente de determinação de 0,83 . No entanto, o lote 2 demonstrou resultados inversos aos demais lotes ao haver porcentagens inferiores de plântulas normais observadas em todos tratamentos com potencial de $-0,2$ à $-1,0 \mathrm{MPa}$.

Apesar de não terem sido constatados resultados significativos para o teste de germinação, observou-se que quase a totalidade dos tratamentos de condicionamento fisiológico para os lotes 1 e 3, proporcionou resultados superiores às sementes não condicionadas (testemunha). Para as sementes do lote 2, nenhum tratamento de condicionamento fisiológico apresentou porcentagem de plântulas normais superior à da testemunha. 


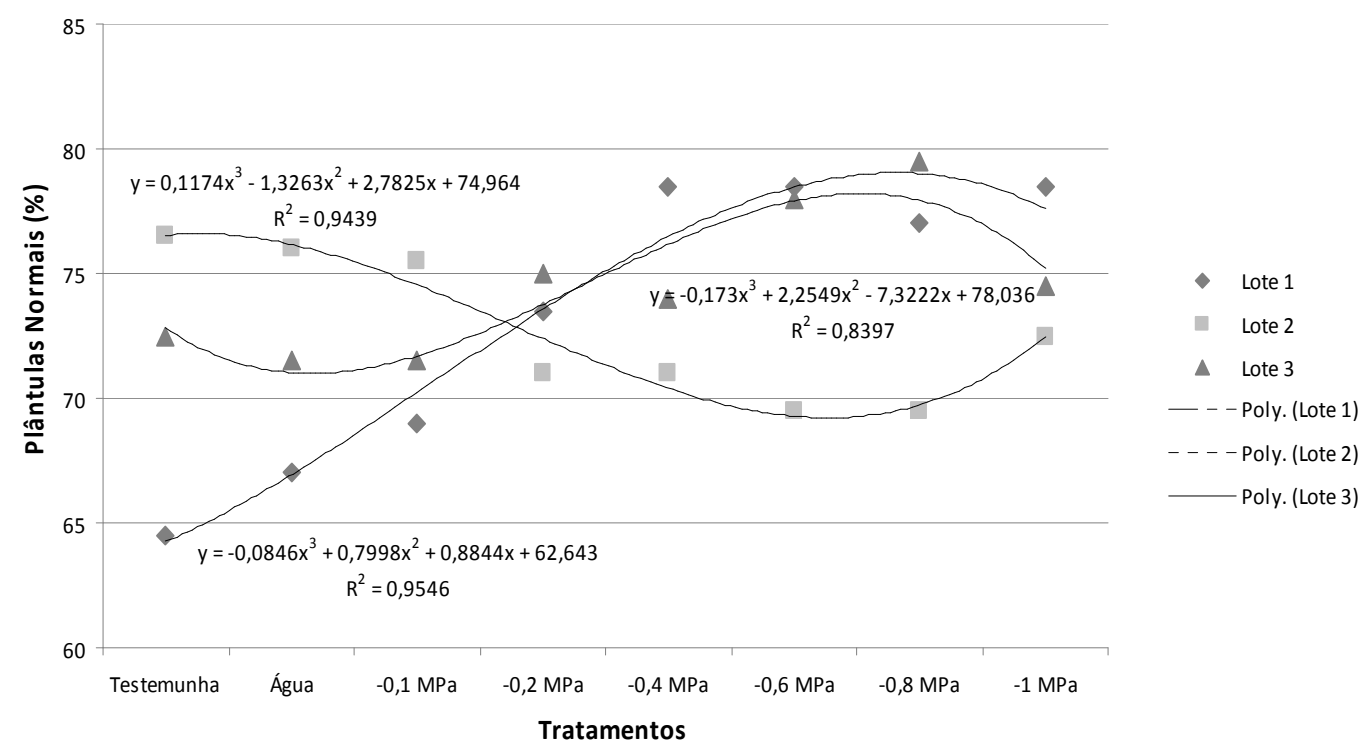

FIGURA 1. Plântulas normais (\%) obtidas na primeira contagem do teste de germinação para as sementes de milheto dos lotes 1, 2 e 3 (cultivar BRS 1501) não condicionadas, condicionadas com água em potencial

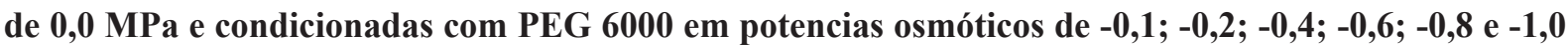
MPa.

Resultado obtido por Carvalho (2000), para diferentes lotes de sementes de sorgo, indicou que a hidratação das sementes por 10 horas e os condicionamentos com potenciais de $-1,2$ e zero MPa aumentaram a velocidade de emergência e de estabelecimento das plântulas. Para o condicionamento osmótico de sementes de Brachiaria brizantha, Bonome et al. (2006) constataram que as soluções aeradas de PEG 6000, $\mathrm{KNO}_{3}$ e da mistura PEG $6000+\mathrm{KNO}_{3}$, por um período de 12 horas, tiveram aumento na velocidade de protrusão radicular em relação à testemunha.

Como observado na Tabela 4 e Figura 2, foram constatadas observações semelhantes na avaliação de envelhecimento acelerado, com variações significativas para todas as variáveis, além de um ajuste cúbico para a porcentagem de plântulas normais, cujo coeficiente de determinação de 0,96 explica quase a totalidade da variação para o lote 1 , que novamente apresentou o menor número de plântulas normais para as sementes não condicionadas. No entanto, para os lotes 2 e 3, não foram observados nenhum valor superior às sementes não condicionadas, com exceção do tratamento com potencial osmótico de -1,0 MPa para o lote 3 .

Bittencourt et al. (2004) obtiveram resultados similares para as sementes de aspargo, para os quais o condicionamento osmótico aumentou significantemente a germinação, porém apenas para as sementes de menor qualidade fisiológica, além de que os resultados do condicionamento osmótico foram mais expressivos para a velocidade de emergência e para o crescimento das plântulas.

No caso da avaliação de condutividade elétrica, a análise de variância indicou que há significância apenas para lotes e tratamentos, sem haver interação entre as demais variáveis (Tabela 4). Assim, como observado na Figura 3, o efeito do condicionamento fisiológico, avaliado pelos diferentes potencias osmóticos obtidos com os tratamentos com água e com PEG 6000, apresentou relação cúbica para a condutividade elétrica de todos os lotes, expresso em $\mu \mathrm{S} . \mathrm{cm}^{-1} \mathrm{~g}^{-1}$ de semente, com um coeficiente de determinação de 0,$82 ; 0,82$ e 0,81 para os lotes 1,2 e 3 respectivamente. 
Os resultados do teste de condutividade elétrica indicam que, apesar dos tratamentos de condicionamento fisiológico terem permitido a reorganização das membranas, em função da quantidade menor de eletrólitos liberada pelas sementes na água (Krzyzanowski et al., 1999), as alterações não foram suficientes para afetar a germinação, a emergência das plântulas e o índice de velocidade de emergência das plântulas (IVE) das sementes não condicionadas (Figuras 4,5 e 6 ), as quais, muitas vezes, apresentaram resultados inferiores aos dos tratamentos com condicionamento, mas que não foram suficientes para causar diferenças significativas, como indicado pela análise de variância (Tabela 4). O qual também pode ser observado na avaliação de teor de água. (Figura 7).

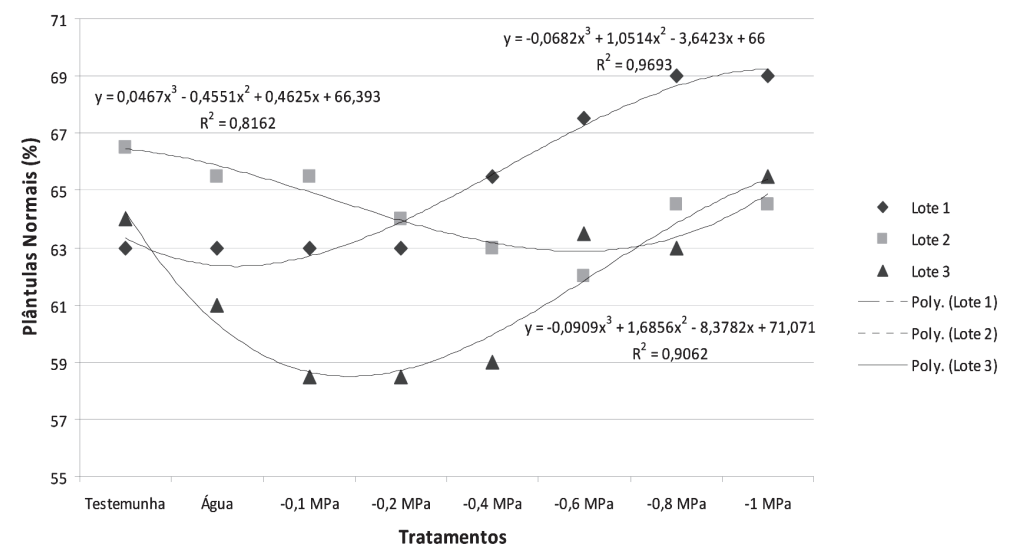

FIGURA 2. Plântulas normais (\%) obtidas após o teste de envelhecimento acelerado para as sementes de milheto dos lotes 1, 2 e 3 (cultivar BRS 1501) não condicionadas, condicionadas com água em potencial de 0,0 MPa e condicionadas com PEG 6000 em potencias osmóticos de -0,1; -0,2; -0,4; -0,6; -0,8 e -1,0 MPa.

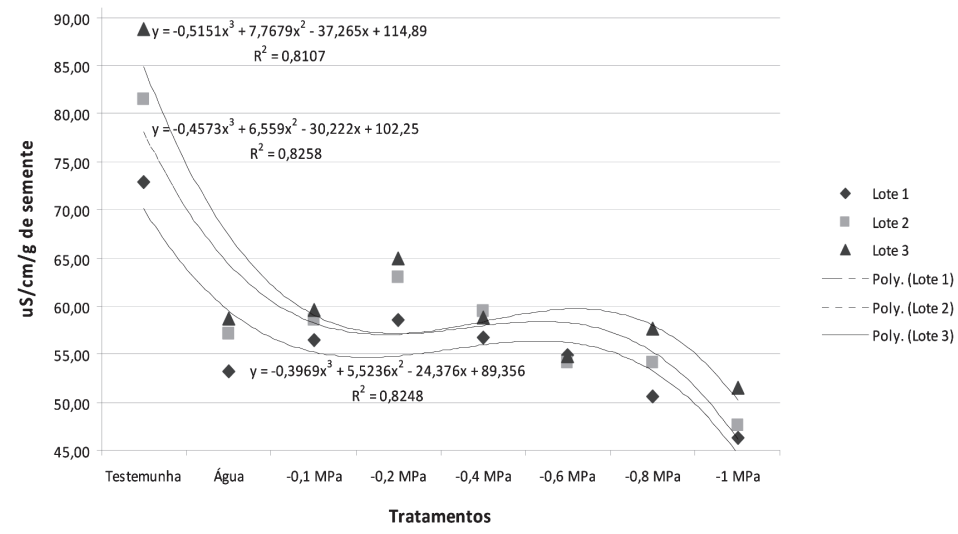

FIGURA 3. Resultados de condutividade elétrica obtidos para as sementes de milheto dos lotes 1, 2 e 3 (cultivar BRS 1501) não condicionadas, condicionadas com água em potencial osmótico de 0,0 MPa e condicionadas com PEG 6000 em potencias osmóticos de -0,1; -0,2; -0,4; -0,6; -0,8 e -1,0 MPa. 


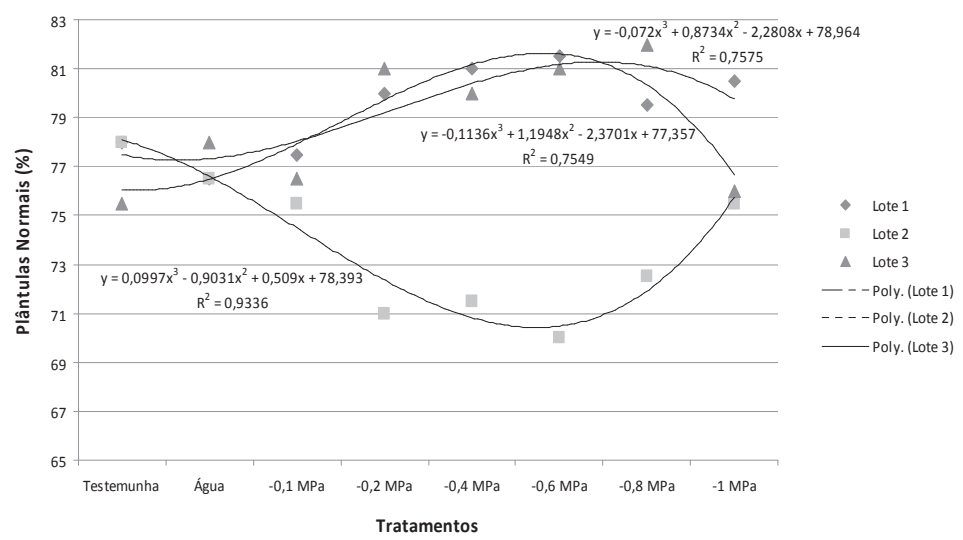

FIGURA 4. Porcentagem de plântulas normais observadas no teste de germinação para as sementes de milheto dos lotes 1, 2 e 3 (cultivar BRS 1501) não condicionadas, condicionadas com água em potencial osmótico de 0,0 MPa e, condicionadas com PEG 6000 em potencias osmóticos de -0,1; -0,2; -0,4; -0,6; -0,8 e -1,0 MPa.

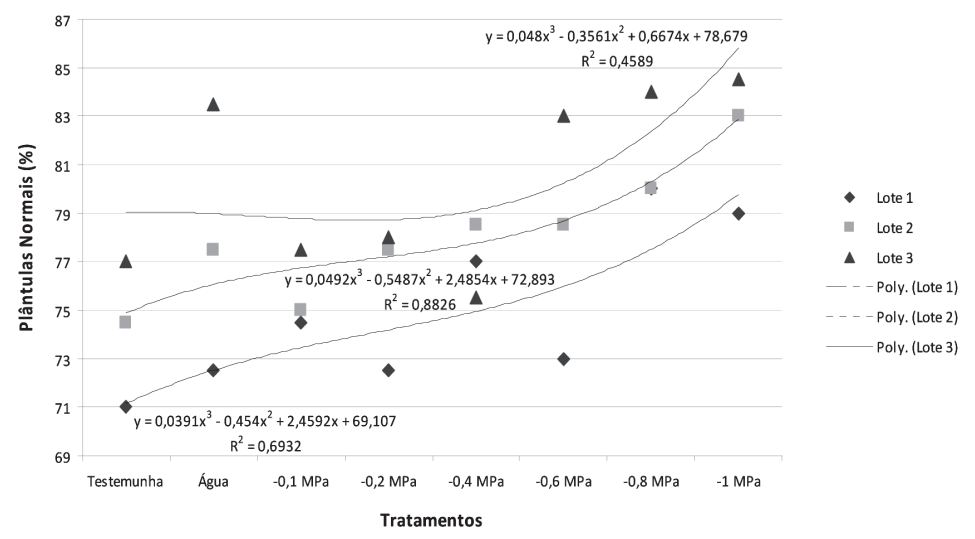

FIGURA 5. Plântulas normais (\%) obtidas no teste de emergência da plântula para as sementes de milheto dos lotes 1, 2 e 3 (cultivar BRS 1501) não condicionadas, condicionadas com água em potencial de 0,0 MPa e condicionadas com PEG 6000 em potencias osmóticos de -0,1; -0,2; -0,4; -0,6; -0,8 e -1,0 MPa.

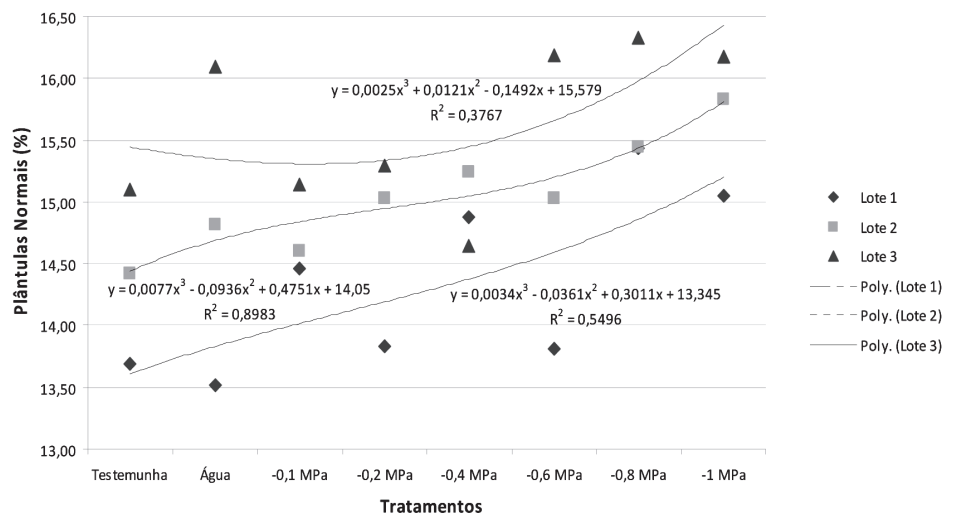

FIGURA 6. Porcentagem de plântulas normais obtidas no teste de índice de velocidade de emergência da plântula para as sementes de milheto dos lotes 1, 2 e 3 (cultivar BRS 1501) não condicionadas, condicionadas com água em potencial de 0,0 MPa e condicionadas com PEG 6000 em potencias osmóticos de -0,1; -0,2; -0,4; -0,6; -0,8 e -1,0 MPa. 


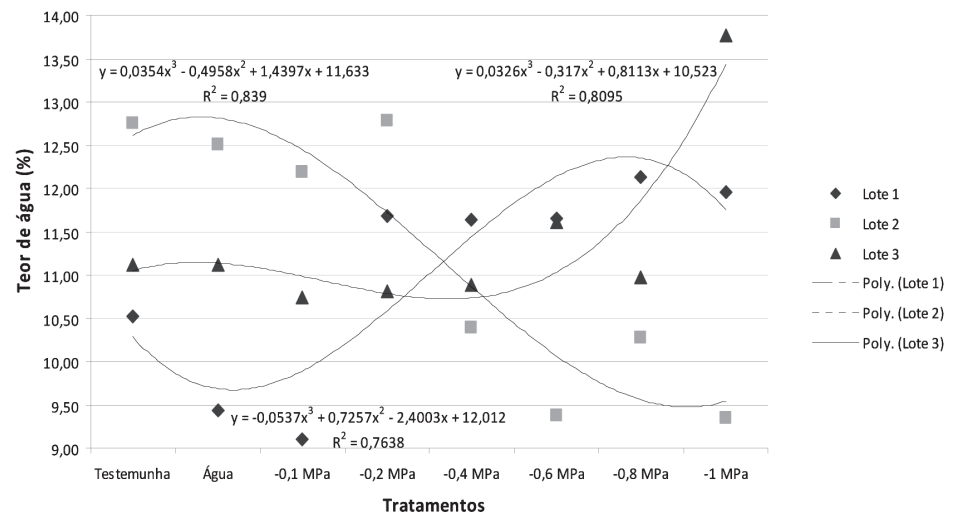

FIGURA 7. Teor de água observado para os lotes 1,2 e 3 de sementes de milheto (cultivar BRS 1501) não condicionadas, condicionadas com água em potencial de 0,0 MPa e condicionadas com PEG 6000 em

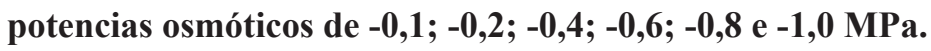

\section{CONCLUSÃO}

O condicionamento fisiológico das sementes de milheto, utilizando água ou PEG 6000, não interfere no desenvolvimento inicial das plântulas.

\section{AGRADECIMENTOS}

Ao CNPq, por dispor dos recursos necessários para o desenvolvimento do projeto e, à Escola Superior de Agricultura Luiz de Queiroz (USP), por fornecer todo o apoio técnico, científico e estrutural.

\section{REFERÊNCIAS}

ABDULRAHMANI, B.; GHASSEMI-GOLEZANI, K.; VALIZADEH, M.; FEIZI, V.A.S.L. Seed priming and seedling establishment of barley (Hordeum vulgare L.). Journal of Food, Agriculture \& Environment, v.5, p.179-184, 2007.

ANWAR, A.K.; KAR-LING, T.; KNYPL, J.S.; BORKOWSKA, B.; LOYD, E.P. Osmotic conditioning of seed: physiological and biochemical changes. Acta Horticulturae, v.1, n.83, p.267-278, 1978.

BEWLEY, J.D.; BLACK, M. Seeds: physiology of development and germination. 2.ed. New York: Plenum Press, 1994. 445p.
BITTENCOURT, M.L.C.; DIAS, D.C.F. dos S.; DIAS, L.A. dos S.; ARAÚJO, E.F. Efeito do condicionamento osmótico das sementes na germinação e no crescimento das plântulas de aspargo. Revista Brasileira de Sementes, v.26, n.1, p.50-56, 2004.

BONOME, L.T.S.; GUIMARÃES, R.M.; OLIVEIRA, J.A.; ANDRADE, V.C.; CABRAL, P.S. Efeito do condicionamento osmótico em sementes de Brachiaria brizantha cv. Marandu. Ciência Agrotecnologia, v.30, n.3, p.422-428, 2006.

BRASIL. Ministério a Agricultura e reforma Agrária. Secretária Nacional de Defesa Agropecuária. Departamento Nacional de Produção Vegetal. Coordenação de Laboratorio Vegetal. Regras para Análise de Sementes. BRASÍLIADF, 1992. 365p

CAPRON, I.; CORBINEAU, F.; DACHER, F.; JOB, C.; CÔME, D.; JOB, D. Sugarbeet seed priming: effects of priming conditions on germination, solubilization of 11-S globulin and accumulation of LEA proteins. Seed Science Research, v.10, p.243-254, 2000.

CARVALHO, L.F.; MEDEIROS-FILHO, S.; ROSSETTI, A.G.; TEÓFILO, E.M. Condicionamento osmótico em sementes de sorgo. Revista Brasileira de Sementes, v.22, n.1, p.185-192, 2000.

CHOJNOWSKI, M., CORBINEAU, F.; CÔME, D. Physiological and biochemical changes induced in sunflower seeds by osmopriming and subsequent drying, 
storage and aging. Seed Science Research, v.7, p.323 $331,1997$.

FANAN, S; NOVEMBRE, A.D.L.C. Condicionamento fisiológico de sementes de berinjela. Bragantia, v.66, p.675-683, 2007.

GARCIA, D.C.; MENEZES, N.L. de. Teste de envelhecimento precoce para sementes de azevém, aveia preta e milheto. Ciência Rural, v.29,n.2, p.233-237, 1999.

GASPAR, C.M.; NAKAGAWA, J. Teste de condutividade elétrica em função do período e da temperatura de embebição para sementes de milheto. Revista Brasileira de Sementes, v.24, n.2, p.82-89, 2002.

HEYDECKER, W; COOLBEAR, P. Seed treatments for improved performance - survey and attempted prognosis. Seed Science and Technology, v.5, p.353-425, 1977.

JETT, L.W.;WELBAUM, G.E.; MORSE，R.D. Effects of matric and osmotic priming treatments on broccoli seed germination. American Society for Horticultural Science, v.121 p.423-429, 1996.

KRYZANOWSKI, F.C.; VIEIRA, R.D.; FRANÇA NETO, J.B. Vigor de sementes: conceitos e testes. Londrina: ABRATES, 1999. 218p.

MWALE, S.S., HAMUSIMBI, C.; MWANSA K. Germination, emergence and growth of sunflower (Helianthus annuus L.) in response to osmotic seed priming. Seed Science and Technology, v.31, p.199-206, 2003.

NAKAGAWA, J. Testes de vigor baseados no desempenho das plântulas. In: KRZYZANOWSKI, F.C.; VIEIRA, R.D. e FRANÇA NETO, J.B. Vigor de sementes: conceitos e testes. Londrina: ABRATES, p.2.1 - 2.24, 1999.
PARERA, C.A.; CANTLIFFE, D.J. Presowing seed priming. Horticultural Reviews, v.16, p.109-141, 1994.

PRISCO, J.T.; BAPTISTA HADDAD, C.R.; PINHEIRO BASTOS, J.L. Hydration-dehydration seed pre-treatment and its effects on seed germination under water stress conditions. Revista Brasileira de Botânica, v.15, p.31-35, 1992.

SALTON, J.C.; KICHEL, A.N. Milheto: alternativa para cobertura do solo e alimentação animal. Informações Agronômicas, n.80, p.8-9, 1997.

SIVRITEPE, H.O.; ERIS, A. The effects of post-storage priming treatments on viability and repair of genetic damage in pea seeds. Acta Horticulturae, v.517, p.143149,2000 .

SMITH, P.T.; COBB, B.G. Accelerated germination of pepper seed by priming with salt solution and water. Horticultural Science, v.26, p.417-419, 1991.

TALLOWIN, J.R.B.; ROOK, A.J.; BROOKMAN, S.K.E. The effects of osmotic pre-sowing treatment on laboratory germination in a range of wild flower species. Annals of Applied Biology, v.124, p.363-370, 1994.

VENKATASUBRAMANIAN, A.; UMARANI, R. Evaluation of seed priming methods to improve seed performance of tomato (Lycoperison esculentum), eggplant (Solanum melongena) and chilli (Capsicum annum). Seed Science And Technology, v.35, p.487-493, 2007.

VIEIRA, R.D.; CARVALHO, N.M. Testes de vigor em sementes.Jaboticabal: FUNEP, 1994.164p.

VILLELA, F.A; FILHO, L.D.; SEQUEIRA, E.L. Tabela de potencial osmótico em função da concentração de polietileno glicol 6000 e da temperatura. Pesquisa Agropecuária Brasileira, v.26, n. 11/12, p.1957-1968, 1991. 